\title{
Controlled trial of a collaborative primary care team model for patients with diabetes and depression: Rationale and design for a comprehensive evaluation
}

Jeffrey A Johnson ${ }^{1,2^{*}}$, Fatima Al Sayah ${ }^{1,2}$, Lisa Wozniak², Sandra Rees², Allison Soprovich², Constance L Chik ${ }^{3}$, Pierre Chue ${ }^{4,5}$, Peter Florence ${ }^{4}$, Jennifer Jacquier ${ }^{3}$, Pauline Lysak ${ }^{5}$, Andrea Opgenorth ${ }^{3}$, Wayne J Katon ${ }^{6}$ and Sumit R Majumdar ${ }^{2,3}$

\begin{abstract}
Background: When depression accompanies diabetes, it complicates treatment, portends worse outcomes and increases health care costs. A collaborative care case-management model, previously tested in an urban managed care organization in the US, achieved significant reduction of depressive symptoms, improved diabetes disease control and patient-reported outcomes, and saved money. While impressive, these findings need to be replicated and extended to other healthcare settings. Our objective is to comprehensively evaluate a collaborative care model for comorbid depression and type 2 diabetes within a Canadian primary care setting.

Methods/design: We initiated the TeamCare model in four Primary Care Networks in Northern Alberta. The intervention involves a nurse care manager guiding patient-centered care with family physicians and consultant physician specialists to monitor progress and develop tailored care plans. Patients eligible for the intervention will be identified using the Patient Health Questionnaire-9 as a screen for depressive symptoms. Care managers will then guide patients through three phases: 1) improving depressive symptoms, 2) improving blood glucose, blood pressure and cholesterol, and 3) improving lifestyle behaviors. We will employ the RE-AIM framework for a comprehensive and mixed-methods approach to our evaluation. Effectiveness will be assessed using a controlled "on-off" trial design, whereby eligible patients would be alternately enrolled in the TeamCare intervention or usual care on a monthly basis. All patients will be assessed at baseline, 6 and 12 months. Our primary analyses will be based on changes in two outcomes: depressive symptoms, and a multivariable, scaled marginal model for the combined outcome of global disease control (i.e., A1c, systolic blood pressure, LDL cholesterol). Our planned enrolment of 168 patients will provide greater than $80 \%$ power to observe clinically important improvements in all measured outcomes. Direct costing of all intervention components and measurement of all health care utilization using linked administrative databases will be used to determine the cost-effectiveness of the intervention relative to usual care.
\end{abstract}

Discussion: Our comprehensive evaluation will generate evidence to reliability, effectiveness and sustainability of this collaborative care model for patients with chronic diseases and depression.

Trials registration: Clintrials.gov Identifier: NCT01328639

Keywords: Primary care, Collaborative, Diabetes, Depression, Controlled trial, Health services research

\footnotetext{
* Correspondence: jeff.johnson@ualberta.ca

'Department of Public Health Sciences, University of Alberta, Edmonton,

Canada

${ }^{2}$ ACHORD, University of Alberta, Edmonton, Canada

Full list of author information is available at the end of the article
} 


\section{Background}

Depression is one of the most common co morbidities in people with diabetes, present in $15-30 \%$ of patients with type 2 diabetes [1], at rates that are $30-40 \%$ higher than the general population $[1,2]$. Despite this, less than $50 \%$ of patients are recognized as having depression within the health care system $[1,2]$. Depression itself is a risk factor for the development of type 2 diabetes [3-5], and it is associated with adverse diabetes-related outcomes [6-9]. For example, comorbid depressive disorders in people with diabetes are associated with poorer selfcare behaviors $[10,11]$ worse glycemic control, higher risk of microvascular and microvascular diabetes-related complications [8-11], decreased quality of life and psychological well-being $[2,12,13]$, and substantially higher health care costs $[6,14,15]$. The implications of untreated depression on long-term morbidity and mortality are even more significant when one considers that depression tends to be a recurrent condition, with $79 \%$ of diabetic patients with depression relapsing over a 5-year period with an average of 4 or more episodes $[13,16]$. In turn, diabetes may worsen the course of depression $[4,16]$. In fact, having one or more chronic medical condition, such as diabetes, increases the likelihood of developing a major depressive episode [17].

Although the majority of individuals with diabetes and depression are treated in primary care settings [18], only a minority of these individuals receive adequate treatment for depression $[6,10,18]$. Indeed, despite its high prevalence, less than one-half of all patients with depression are diagnosed or adequately treated $[19,20]$. Even primary care patients with established and treated depression receive only $48 \%$ of recommended management with both medication and psychotherapy [20]. It is also true that these rates of adequate treatment are much lower for those with diabetes, given that up to one-half of these patients have undiagnosed depression $[1,19,20]$. Depression has also been reported to be an important barrier to enhancing self-management, quality of care and outcomes in individuals with diabetes in primary care settings $[18,21,22]$.

Traditional approaches to improving primary care of patients with complex comorbid chronic illnesses typically involves "carve-out" disease management programs, that is, delivering care for each condition, one disease at a time. Such single-disease management programs have been shown to be effective in improving control of conditions such as heart failure [23], diabetes [24,25], and depression [26]. However, a recent systematic review and meta-analysis of interventions for depressive disorders in patients with diabetes concluded that pharmacologic and collaborative care interventions were primarily aimed at and succeeded in the reduction of depressive symptoms, but, in general, had no effect on glycemic control [27]. It was suggested that individuals with comorbid physical and psychological problems require a far more integrated approach of care that targets such conditions collectively, and that management of these comorbid conditions should not be done separately [27].

This concept was recently proven in a pair of randomized trials investigating the efficacy of a casemanagement collaborative care model for patients with diabetes and depression in the primary care setting of Group Health Cooperative in Washington State [28,29]. In the first trial, a case-management approach proved effective in reducing depressive symptoms, but did not result in improved glycemic control [28]. In the second study, the case-managed collaborative care model was expanded in scope, aimed at achieving improvements of depressive symptoms and cardio-metabolic markers in individuals with depression and poorly controlled diabetes or heart disease [29]. In both cases, a nurse care manager guided patient-centered care with family physicians and consultant physician specialists. In the second study the intervention initially focused on the treatment of depression, but also aimed at management of diabetes and cardiovascular risk factors (e.g. high blood pressure, elevated lipids, elevated A1c), as well as lifestyle health-related behaviors. The trial involved 214 patients from 151 physicians in 14 primary care clinics. Patients in the intervention group had greater overall 12-month improvement across A1c (difference, 0.58\%), LDL cholesterol (difference, $0.2 \mathrm{mmol} / \mathrm{L}$ ), systolic blood pressure (difference, $5.1 \mathrm{~mm} \mathrm{Hg}$ ), and SCL-20 depression scores (difference, 0.40 points $)(\mathrm{P}<0.001)$. Patients in the intervention group also were more likely to have one or more adjustments of antihypertensive medications $(\mathrm{P}<0.001)$, insulin $(\mathrm{P}=0.006)$, and antidepressant medications $(\mathrm{P}<0.001)$, and they had better quality of life $(\mathrm{P}<0.001)$ and greater satisfaction with care $(\mathrm{P}<0.001)$. Patients in the intervention group had a mean of 10.0 in-person and 10.8 telephone visits with the nurse care manager over the 12-month period. The estimated mean cost per patient for this intervention, including all nurse contacts, specialist physician consultations, and information system support, was $\$ 1,224$ (USD) in 2009 [29]. However, these intervention costs were offset by savings in total medical costs; over a 24-month period the intervention was associated with approximately $\$ 600$ cost savings per patient compared to usual primary care [30].

While impressive, these findings need to be replicated and extended to other healthcare settings before the intervention model can be widely adopted or recommended. We took the previous randomized controlled trials as evidence of the efficacy of this case-managed collaborative model of care $[28,29]$. We therefore proposed a pragmatic approach in the implementation and evaluation of the collaborative care intervention in Primary Care Networks 
(TeamCare-PCN), and will employ a mixed-methods approach, based on the RE-AIM framework [31]. The RE-AIM framework examines five dimensions: Reach into target populations; Effectiveness; Adoption by target settings, institutions, and staff; Implementation, including consistency and cost of delivery; and Maintenance of effects in both individuals and settings over time. Thus, while a major focus of our protocol is on effectiveness, based on changes in clinical outcomes, applying the complete RE-AIM framework will allow us to determine the broader impact and transferability of the TEAM care model in the Alberta context.

\section{Methods}

\section{Overall study design}

We will evaluate the effectiveness (i.e., the "E" in REAIM) of the TeamCare-PCN intervention using a controlled pragmatic trial design. We have implemented a variant of a practical design referred to as "cohort multiple RCT" (Figure 1) [32]. Patients with type 2 diabetes registered at PCNs will be invited to participate in an ongoing, annual survey as part of a larger Alberta's Caring for Diabetes (ABCD) Cohort Study. Initial contact with cohort participants includes the administration of the Patient Health Questionnaire, a brief depression screening survey, and if positive for depressive symptoms, respondents will be invited to participate in the TeamCare-PCN study. We will allocate eligible participants to the intervention and usual care arms using an "on-off" time series (Figure 1); all participants will be assessed at baseline, 6 and 12 months.

Our decision to employ a pragmatic approach was based on a number of factors. First, the efficacy of the intervention has been established $[28,29]$, so it is important that external validity now be accorded similar attention to the usual concerns related to internal validity [33-35]. Second, various forms of case-management have generally shown to be effective in improving quality of care for patients with diabetes [36]. Third, the effectiveness, applicability, and feasibility of the intervention have only been established in the urban managed care setting in the US [29]. Testing this intervention in a Canadian primary care setting is crucial to claim its effectiveness and applicability to the Canadian context. Finally, limitations in the available scientific information often impede the efforts of health policy makers and care providers in making evidenceinformed policies for new and existing health technologies and interventions [33]. This results in allocating scarce healthcare dollars to interventions where the effectiveness and cost-effectiveness in routine clinical settings have not been evaluated [34,35,37]. While an economic evaluation of the original TEAM Care intervention was undertaken from the perspective of a US managed care organization provider [30], it is important to adopt a pragmatic approach to evaluate the effectiveness and cost-effectiveness of the TeamCare-PCN intervention in the Canadian context, and make this information available to support local health policy making and resource allocation.

\section{Hypotheses}

We hypothesize the TeamCare-PCN intervention will reduce depressive symptoms, increase achievements of targets for cardio-metabolic measures, improve lifestyle behaviors, and be cost-effective. Furthermore, we anticipate this intervention will be acceptable and feasibly implemented in the PCN environment.

\section{Setting and population}

TeamCare-PCN will be conducted in collaboration with four PCN in non-metro Alberta. A PCN is akin to the

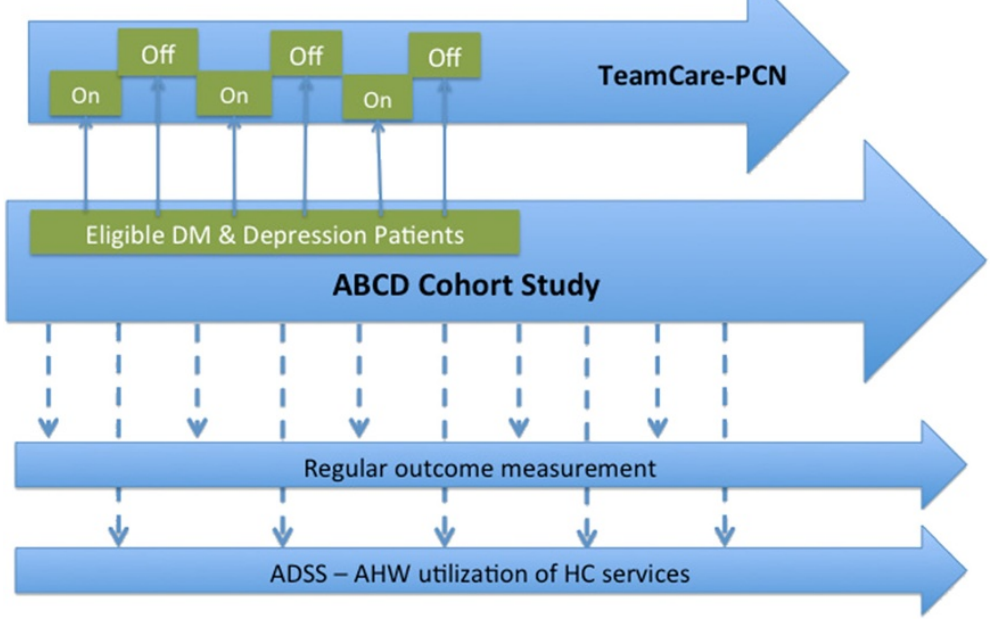

Figure 1 Schematic of Overall Design for TeamCare-PCN Study. 


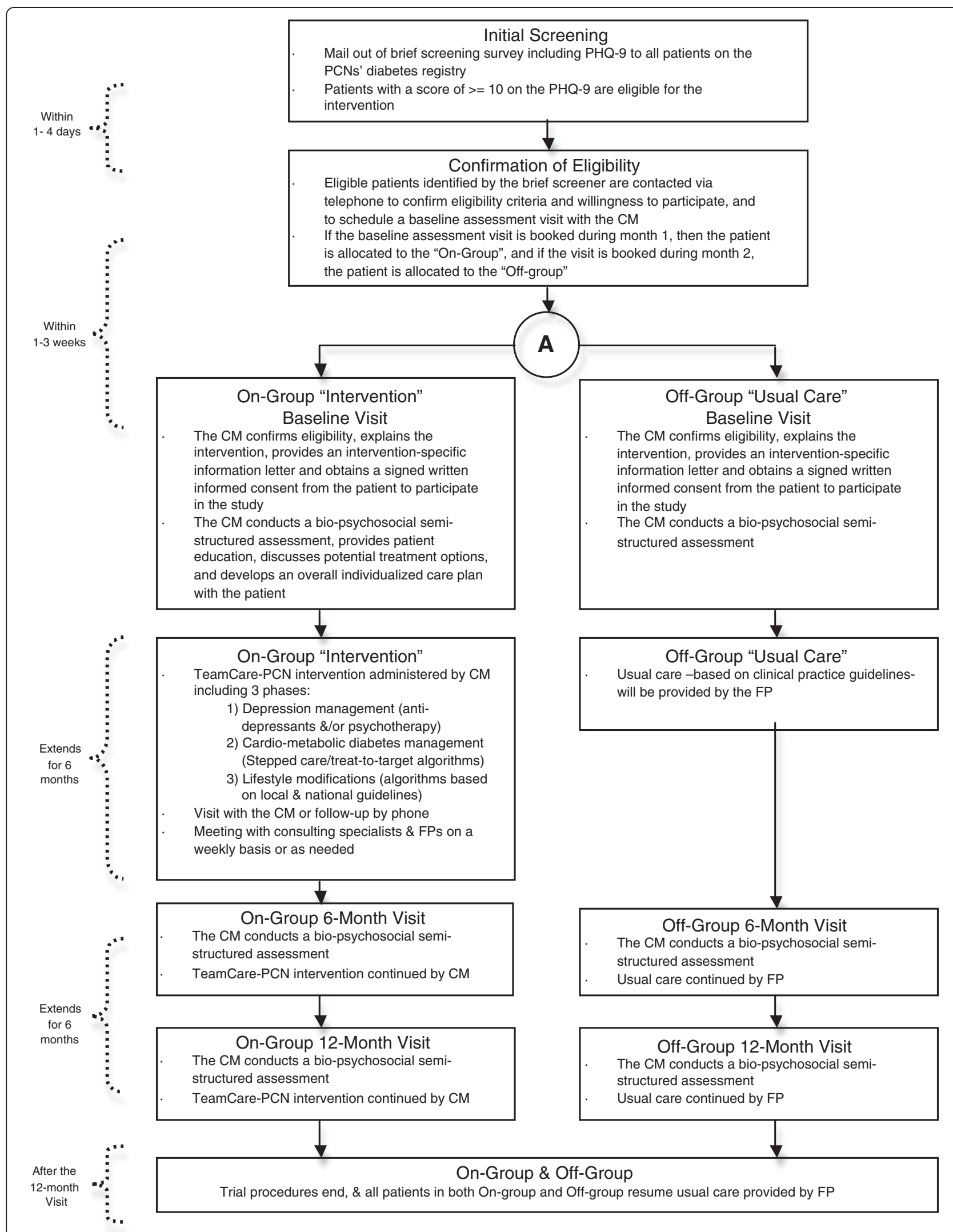

Figure 2 TeamCare-PCN Study Procedures. 
"medical home" concept [38], established as a network of primary care physicians in a given geographical area. Through the provincial Primary Care Initiative framework, funding is provided based on an approved business plan for the provision of primary care services to the local population. Each network has the flexibility to develop programs and to provide services in a way that works locally to meet the specific needs of patients. Funding may be used to establish central PCN office/ clinic space, and hire allied health professionals, such as nurses, dieticians, pharmacists, or therapists. At the time of the launch of this study, there were 40 PCNs operating throughout Alberta, with about $80 \%$ of eligible family physicians working within a PCN. We elected to partner with PCNs outside of the larger metro centers because these cities already have greater access to specialist care as well as more established regional diabetes care and management programs than the non-metro PCNs. Collectively, the four participating study PCNs represent 140 general physicians and approximately 180,000 patients, with an estimated 10,000 patients with type 2 diabetes.

\section{Eligibility criteria}

Inclusion Criteria:

- Have type 2 diabetes and under the care of a PCN family physician and be

- 18 years of age or older and

- Score > =10 on the PHQ-9 [29,39,40] and

- Speak English and have adequate hearing to complete telephone interviews and

- Be willing and able to provide written informed consent to participate

\section{Exclusion Criteria:}

- Severe and/or terminal physical illness (e.g. heart disease, renal failure, cancer, major organ failure) or

- Serious and/or severe mental or psychiatric illness (e.g. bi-polar disorder or schizophrenia, use of anti-psychotic or mood stabilizer medication, or cared for by a psychiatrist); patients taking anti-depressants or receiving supportive psychotherapy from non-psychiatrists would be eligible or

- Pregnant or breastfeeding or

- Live in long-term care facility or

- Already participating in other clinical trials

\section{Recruitment and allocation}

Recruiting participants into TeamCare-PCN involves three steps. First, a screening survey accompanied with an endorsement letter from the PCNs will be mailed out to all patients with type 2 diabetes on the PCNs' diabetes registries. This survey asks about age, the ability to read and speak English, having type 2 diabetes, length of time since diagnosis, and screens for depressive symptoms. Second, after potential participants have completed and returned the screening survey, PCN staff will contact eligible participants to confirm all eligibility criteria and if the participant is willing to participate, and schedule a baseline assessment visit. Third, during the baseline visit, the Care Manager (CM) will confirm eligibility, explain the intervention, provide an intervention-specific information letter and obtain a signed written informed consent from the patient to participate in the study.

Participants will be allocated to study groups using a previously successful "on-off" group assignment method (Figure 1) $[39,41,42]$. Eligible and consenting respondents who book for a baseline assessment with the CM during month 1 will be allocated to the intervention arm (ON-group). Those who book the baseline assessment in month 2 will be allocated to the usual care arm (OFFgroup). This allocation process will continue until the target sample size is recruited. This method has been used in many quality improvement studies, reliably leads to balance in measured [and unmeasured] patient characteristics $[39,41,42]$, and meets study design criteria for internal validity sufficient to permit inclusion in the Cochrane Collaborations' Effective Practice and Organization of Care (EPOC) systematic reviews [40]. Because all four sites are involved in both "on" and "off" phases, this particular study design also balances case mix and controls for Hawthorne or volunteer effects, as well as issues related to "institutional learning" over time $[39,40,42]$.

\section{TeamCare-PCN intervention Overview}

The TeamCare- $\mathrm{PCN}$ intervention involves a registered nurse Care Manager (CM), who coordinates collaborative team management for patients with diabetes and depression. Individuals with diabetes will be screened for depressive symptoms using the PHQ-9; patients with a score of $>=10$ on the PHQ- 9 are eligible for the intervention $[43,44]$. The PHQ-9 has been used in a number of interventions for screening of depressive symptoms in primary care [44], including among diabetic patients [45], and specifically in the efficacy study of the TEAM Care intervention [29].

The goal of the intervention is to reduce depressive symptoms, achieve targets for cardio-metabolic measures and improve lifestyle behaviors. The intervention includes three phases: (1) managing depression and improving depressive symptoms, (2) managing diabetes and controlling blood glucose, blood pressure and cholesterol, and (3) improving lifestyle behaviors such as healthy eating, physical activity and smoking cessation. 
The CM will coordinate the TeamCare-PCN intervention, while the family physician will remain responsible for final treatment decisions and all prescriptions. The $\mathrm{CM}$ will consult with specialists (psychiatrist and internist/endocrinologist) to consider management options depending on patients' needs and desires. The CM will use locally endorsed evidence-based algorithms to provide recommendations for changes in the treatment plan, and in collaboration with specialists and the patients' family physician, also support the implementation of the patients' individualized care plan. Using a patient-centered focus, the CM will partner with the patient to develop a shared definition of problems, provide education and support, agree on specific targets/goals and individualized action plan, offer support and problem solving to optimize selfmanagement, and closely monitor treatment adherence and outcomes.

\section{Patient management}

Patients entering the intervention will have a two-hour baseline appointment with the CM. This first visit will include a bio-psychosocial semi-structured assessment (reviewing medical history, previous treatments for depression and diabetes), patient education, potential treatment options (anti-depressant medications and/or psychotherapy) and developing an overall individualized care plan.

As mentioned, the intervention will consist of 3 phases; the first focusing on depression management, the second on cardio-metabolic diabetes management, and the third on general lifestyle modifications. A treatto-target/stepped care approach will be used at each phase of the intervention. Recommended treatments have been based on algorithms that were developed in collaboration with the PCNs by compiling various guidelines and sources, such as extant clinical practice guidelines and consulting experts in the field. The CM will actively follow-up by telephone or in person one to two times per month to re-assess symptoms, and assist and support patients in achieving treatment goals. The CM will also have weekly meetings with the consulting specialists to review new cases and patient progress, and then communicate team treatment recommendations to the primary care physician.

The depression management phase (Phase 1) will involve the use of anti-depressant medications and/or referral for psychotherapy, as determined by the CM and the family physician (with study psychiatrist consultation as needed by the $\mathrm{CM}$ ), tailored to each patient. A twoday training session for $\mathrm{CM}$ and consultant specialists was planned at the beginning of the project, with an annual one-day booster session The CM will be given basic training in three psychotherapeutic techniques during this phase: problem-solving therapy [46-49], behavioral activation [50-54], and motivational interviewing [5557]. Direct referral to the care of a psychiatrist will occur only on failure of two separate trials of anti-depressants, or one trial of anti-depressant in combination with psychotherapy. Once patients have reached remission, the $\mathrm{CM}$ and patient work together towards a relapse prevention plan to help the patient identify when and where to seek help with future depressive symptoms or renewed problems for disease control. The CM will continue to work with patient through Phases 2 and 3 of the intervention.

Stepped care/treat-to-target algorithms for Phase 2 (cardio-metabolic care) were developed in collaboration with health care professionals at the PCNs and study specialists using local and national guidelines. Phase 2 includes working with the CM in analogous fashion to Phase 1, but with a focus on reaching individualized targets for hemoglobin A1c, lipids and blood pressure measures. Phase 3 involves patient education to address lifestyle behaviors such as diet and exercise. Locally developed educational materials and existing PCN support programs will be available for patient referrals.

\section{Usual care}

All participants in TeamCare-PCN will be actively screened for depression and those allocated to usual care (or intervention) will be identified as such to their family physician. For disease management, patients will receive care from their family physician, without additional active support from the CM. Therefore, this group will receive the usual standard care for diabetes and depression from their family physicians based on available clinical practice guidelines. Participants in this group will be assessed for all of the same outcome measurements as intervention patients. A recently published trial concluded that screening for depression with written feedback to patients and physicians resulted in no improvements in depressive symptoms, nor changes in utilization of mental health care services [58]. Thus, in our design, the usual care group is very likely to represent usual care for patients with diabetes and depression.

\section{Outcome measures}

To assess the effectiveness ("E" in RE-AIM) of TeamCare-PCN, we will use two primary outcome measures. First, given that we selected patients on the basis of depressive symptoms, our primary depression-related outcome will be the PHQ-9 scores at 12 months. Second, a global measure of patient-centered improvement (the scaled marginal model, see Analysis below) based on the combination of chronic disease-related clinical outcomes. All outcomes will be measured in all participants (i.e., both groups) at baseline, 6, and 12 months. We will 
secondarily evaluate process indicators for care received, as well as a host of patient-reported outcome measures to determine the overall effectiveness of the TeamCare$\mathrm{PCN}$ intervention.

\section{Depression-related outcome}

The outcome measure for depression will be improvement in PHQ-9 score $[43,44]$. The minimal important difference on the PHQ-9 score is widely considered to be 5 points [44]. A remission of depression symptoms is indicated with a score $<10$ for a period of three consecutive months [29]. Operationally, this can be conceptualized as a continuous score or as a binary outcome: improved vs not, since all participants will have scores greater than 10 as part of their eligibility.

\section{Chronic disease-related clinical outcomes}

Clinical outcome measures include systolic blood pressure (SBP), LDL cholesterol and A1c, demonstrated by achievement of targets or significant improvements as indicated with a $10 \%$ improvement over baseline $[59,60]$. These outcomes will be measured using point-of-care devices that we have standardized and placed in each PCN. Capillary blood samples will be collected from participants to assess A1c and lipid profile. Cardiovascular (blood pressure and resting heart rate) and anthropometric (weight, height, and waist circumference) measurements will also be assessed at clinic visits. Regular, monthly quality assurance checks will be conducted on the point-of-care devices, validated against central laboratory measurements.

\section{Process of care indicators}

Process indicators will include the number of visits with PCN care providers, including CM, family physicians, specialists consults, referrals for mental health care, and use of medications and psychotherapeutic sessions. The time spent with patients will be tracked for all CM contacts. Adjustments to medications and adherence to treatments will also be assessed.

\section{Patient-reported outcomes}

A range of patient-reported outcomes will be collected from all participants by regularly administering previously validated surveys at baseline, 6 and 12 months. Survey sections and measures are outlined below, and a briefer version of the survey will be used at 6-months. These measures of patient-reported outcomes were selected based on extensive literature supporting their psychometric properties and common application in assessments of this patient population

- Health Related Quality of Life: includes assessment of general health status (SF-12 and EQ-5D) [61-64] and diabetes-specific stress (Problem Areas in Diabetes 5-item) [65].

- Health behaviors and self-management: includes assessment of smoking behaviors, alcohol consumption [66], substance use [67], and physical activity [68], and the Summary of Diabetes Self Care Activities (SDSCA) [69].

- Satisfaction with care: using Consumer Assessment of Healthcare Providers and Systems (CAHPS), Adult Primary Care 1.0 [70] and Patient Assessment of Chronic Illness Care (PACIC) [71,72].

- Health Literacy and Self-efficacy: includes assessment of health literacy (3-brief screening questions [73] and self efficacy (Stanford SelfEfficacy for Managing Chronic Disease 6-Item Scale) [74].

\section{Data management}

The depression and medical outcome measures will be entered into a clinical management tracking system as part of the TeamCare-PCN intervention. The data collected in the survey and through clinical measurement will be entered into centralized, web-accessible databases. These study databases will be housed on secure servers in the research offices at the University of Alberta. Double data entry will be conducted and research staff will remain masked to allocation status at all times. Once the study is completed, all data will be exported and merged, based on individually assigned study ID numbers, to form an analyzable dataset. Investigators, research assistants, and analysts will be masked to allocation status at all times.

\section{Data analysis}

As the initial focus of the intervention is on the management of depressive symptoms, we have considered the PHQ-9 as a main primary outcome, and will assess changes in PHQ-9 scores over 12-months between groups, adjusting for baseline PHQ-9 score, using a mixed effects multivariate model. For our second primary outcome of improvements in global disease control, we will employ a multivariate model that jointly tests the changes in multiple clinical outcomes, namely A1c, LDL cholesterol and systolic blood pressure [29]. Using the same analytic approach as in the recently published RCT of this intervention, we will apply a scaled marginal model $[29,75]$ to simultaneously compare the change in these continuous outcomes at 12 months, adjusting for the baseline status for each variable. This approach scales the changes in each outcome by its standard errors, and thus the coefficients can be directly interpreted as effect sizes [29]. In either primary outcome analyses, the models will be estimated iteratively and the potential correlations among and between 
outcomes within individuals will be handled using generalized-estimating equation (GEE) models for each outcome [75].

We will also compare the study arms based on the proportion of subjects who achieved a remission of depression (i.e., PHQ- $9<10$ for 3 consecutive months) and the proportion of patients who achieve a clinically important change in the outcomes (that is, achieving a reduction of 5 points on the PHQ-9 [44] or a $10 \%$ or greater improvement over baseline values for A1C, LDL cholesterol and SBP at 12 months) [59,60], using generalized estimating equations and multivariable logistic regression models. This approach will allow us to present and interpret all outcomes in terms of absolute differences and a number-needed-to-treat [76].

For all analyses we will employ an intention-to-treat framework for our primary analysis, using a last-observation-carried-forward method of imputation for subjects who do not have complete follow-up data for primary or secondary outcomes. This approach is conservative as it assumes subjects with missing follow-up data have not changed. In either case, the regression models will accommodate additional covariates, as required, to adjust for PCN site, as well as any post-allocation baseline differences between groups in clinically important (e.g., age, sex) or statistically significant (e.g., p < 0.1) characteristics. This ability to statistically control for potential imbalance may be necessary given the non-random treatment allocation used in our "on-off" design.

\section{Sample size and power considerations}

We estimate that a minimum total sample size of 120 , with 60 in each arm, would provide power of 0.80 to detect a mean difference of 5 points in the PHQ-9 [44], assuming a repeated measures correlation of 0.6 , and 2tailed alpha of 0.05 . This sample size also provides more than $80 \%$ power (two sided alpha $=0.05$ ) to detect any between-group absolute difference in proportions of $15 \%$ or more (e.g., $45 \%$ of usual care patients achieve depression remission vs $60 \%$ of intervention patients) [29]. Anticipating a $40 \%$ attrition rate, we planned to recruit 168 patients in total across our 4 PCN sites. Although the model is implemented in $4 \mathrm{PCN}$ sites, the individual general physicians affiliated with the PCN will carry out the changes in care. While we will include PCN site as a covariate in our analysis, because there are approximately 140 general physicians across these $4 \mathrm{PCN}$ sites, we choose not to further inflate our sample to account for clustering of patients and their outcomes.

\section{Broader RE-AIM evaluation \\ Reach}

Using demographic information and eligibility criteria, a comparison of patient characteristics between the intervention and usual care groups will be conducted to address reach. Aggregate demographic information between participants and non-participants will be compared using population-level data available through the Alberta Diabetes Surveillance System [77]. Information on reach will also be documented through a patient recruitment tracking system, the PCNs' diabetes patient registries, and monthly reports on recruitment submitted by PCN staff.

\section{Implementation, including cost-effectiveness}

Implementation evaluation is used to examine the extent to which an intervention is delivered as planned, particularly in real world practice settings. This type of evaluation explores why an intervention is successful or not, and can contribute to the successful realization of programs in the future. Implementation evaluation of TeamCare-PCN will enhance our contextual understanding and interpretation of why the intervention had an impact or not, in which settings (i.e. PCNs), and for whom. It also provides a mechanism for continuous quality improvement by generating ongoing information. Implementation evaluation is also crucial to determine the sustainability of a program, as it is used to inform future decision-making and strategic planning by identifying critical successful factors for implementation (such as resources, staff qualities, and leadership) and recommendations to mitigate barriers.

We will examine the intended versus actual implementation of TeamCare-PCN through several means: document review; pre/post training survey of CMs to assess knowledge and confidence with the model; usual care checklist documenting organizational priorities and systems to implement the model; baseline, mid- and post-intervention interviews with PCN staff regarding facilitators and barriers to implementation and recommendations for improvement; and participant-observation.

A number of economic evaluations of team-based interventions in patients with diabetes and depression have been conducted [30,78-80]. Incremental cost-utility ratios have been estimated at less than $\$ 400$ per qualityadjusted life year gained [78]. While the consistent economic benefit of these interventions has been demonstrated, these evaluations are highly dependent on many factors including the implementation strategies of these interventions in the primary care settings of the single urban managed care environment in the US. We will therefore conduct an economic evaluation of the TeamCare-PCN implementation, using a similar methodological approach. To do this, we will use primary data collected during the study period, health care utilization data obtained through linkages with administrative databases, as well as an Alberta-based economic model to estimate future diabetes related costs [81]. For 
our economic evaluation models, we will take the perspective of the individual PCN Board as the main decision maker, with a second perspective of the third-party payer, that is, the provincial health care system, along with our analyses focusing on direct medical costs, as this is the most relevant perspective for our decisionmaking partners.

Intervention costs versus usual care costs Costs for the intervention will be estimated using the actual salary and benefits for the Care Manager and Administrative Assistant provided for the intervention plus a $30 \%$ overhead rate for PCN space and management costs [82]. The CM time will be estimated based on the actual visits with intervention patients, for both in-person and telephone contacts, as well as outreach efforts and recordkeeping. Intervention costs will also include a fixed amount for each participant assigned to the intervention program to defray the costs of specialist supervision and the clinical management support.

Health care utilization data Patients enrolled in the study will be asked for permission to access their medical records by providing their personal health number, thus allowing linkage to provincial health care administrative data from Alberta Health and Wellness (AHW) for physician, hospital, and emergency department billing, and pharmaceutical data (for patients 65 years and older). This linkage will allow health care utilization and health care costs to be included in the evaluation. These data sources are regularly monitored as part of the Alberta Diabetes Surveillance System (ADSS) [77].

Long-term economic projection model We have developed a projection model for the future burden of diabetes in Alberta using data collected for the ADSS [81]. Our projection model is based on two elements: epidemiologic trends and costs. To estimate the future incidence of diabetes complications, we will use trends in incidence rates by diabetes status, sex and age group. We will model the longer-term (e.g., at 10-, 20- and 30years) costs and outcomes of the TeamCare-PCN intervention. We will employ a discount factor of $5 \%$ to all future costs and benefits, and perform sensitivity analyses on this discount factor, using rates of $0 \%, 3 \%$ and $10 \%$. Last, we plan to conduct exhaustive one-way, multi-way, and probabilistic sensitivity analyses to ensure our findings are robust $[82,83]$.

\section{Adoption}

We will examine the adoption of TeamCare-PCN by documenting and comparing the characteristics of the participating PCNs. This will be done through document review (e.g., PCN websites, business plans), the usual care checklist (description of participating PCNs - including number of family physicians, number of patients, governance structure, organizational processes and structures), and interviews with PCN staff. Determining the representativeness of the participating PCNs compared to non-participating PCNs represents a challenge and will be dependent on the availability of secondary data to describe the characteristics of all PCNs in Alberta.

\section{Maintenance}

We will also examine the extent to which the effects of the interventions are sustained over time in patients (that is, sustained awareness, knowledge, and management of T2D, depression, and lifestyle behaviors) and at the organizational level of the PCN. This type of information will be gathered through patient reported outcomes (e.g., health behaviors and self-care items) through regular surveys at baseline, 6 and 12 months. These survey items will be collected through the ABCD Cohort Study survey, which will be administered annually for five years after completion of TeamCare-PCN. Also, interviews with PCN staff will be conducted regarding decisions around incorporating the intervention models into future business planning or continuing the use of aspects of the model, such as using the diabetes registry to inform PCN programming, or using screening tools to identify and assess depressive symptoms among people with chronic illness.

\section{RE-AIM data and analysis}

The primary data sources for our broader RE-AIM evaluation activities include the following:

1) Project documents review including patient tracking databases, email communications, and review of secondary data, as available;

2) Participant observation includes assessment of notes generated from meetings with the PCNs and other partners; and,

3) Interviews with the Executive Directors, Chronic Disease Clinical Managers, and the CMs from the 4 participating PCNs. Specialists and family physicians will also be invited to participate.

Interviews will be digitally recorded, transcribed verbatim by an independent transcriptionist and verified for accuracy. All qualitative data sources will be compiled and managed using NVivo 9.0 software. We will take a general inductive approach to analysis of the qualitative data [84], which places fewer restrictions on the content analysis than more constraining approaches such as grounded theory or phenomenology [85]. Within this approach, the evaluation questions related to the RE- 
AIM framework will direct analysis of the data. However, the findings will be derived directly through a content analysis [86].

\section{Ethics and funding considerations}

All patient participants will receive information about the study and the opportunity to ask any questions. Written informed consent will be obtained from participants prior to obtaining any study measurements. Ethics approval for the study and its evaluation has already been granted from the Health Research Ethics Board (HREB \#PRO00012663) at the University of Alberta. The broader evaluation component of this study was also submitted to the HREB for review. However, the Board deemed this component of the study as evaluation and not research; it was deemed to not require ethics review and approval. Regardless, the requirements outlined in the Tri-Council Policy Statement: Ethical Conduct of Research Involving Humans [87] will be followed in this study. Verbal informed consent from participants will be sought prior to any evaluation activities.

The funding for this study is from a contract from the provincial government (Alberta Health and Wellness) to the Alliance for Canadian Health Outcomes Research for Diabetes (ACHORD) Group. The funding source had no role in the design of the study and will have no role in the conduct, analysis or reporting of the study, nor access to the data.

\section{Discussion}

We report the protocol for the design and comprehensive evaluation of a collaborative team model of primary care for patients with comorbid depression and diabetes. Diabetes is a common and increasingly prevalent chronic medical condition. Comorbid depression is common in people living with diabetes, although it often goes unrecognized and therefore untreated. Together, diabetes and depression increase the risk of adverse health outcomes in these patients, including increased mortality and increased heath care utilization, and treatment should be administered using an integrated approach that targets both diabetes and depression collectively. The efficacy of this collaborative care model has been demonstrated, but only within one managed care environment in the US. Our proposal is to evaluate this model of care in the evolving primary care environment in Canada.

We have proposed a pragmatic approach in the study design of the TeamCare-PCN intervention, and will employ a mixed methods approach for our comprehensive evaluation. Therefore, while we will undertake a controlled outcome evaluation based on changes in clinical parameters to determine effectiveness, we have also planned an economic evaluation and qualitative assessments of reach, adoption, implementation and maintenance. This broad evaluation is intended to provide the relevant decision-makers (i.e., provincial funding agencies and primary care networks) with stronger information on which to build business plans for future service delivery. Ultimately, we believe our work will serve as a platform upon which an emerging model of primary care can incorporate an effective and cost-effective depression intervention into the management of individuals with type 2 diabetes, and as a framework for implementing and evaluating similar interventions for other chronic conditions.

\section{Competing interests}

Dr. Chue has received research and travel grants from Janssen, Pfizer, Astra Zeneca, Lund beck, Bristol Myers Squibb and Eli Lilly as a researcher and speaker.

Dr. Katon has received support to serve on advisory boards from Eli Lilly and has received honorariums for lectures from Pfizer, Forest, and Eli Lilly.

The remaining authors declare that they have no competing interests.

\section{Authors' contributions}

JAJ and SRM conceived and designed the study, based on a previous study led by WJK. WJK served as a consultant in the implementation phase of this study. JAJ and FAS drafted this manuscript, with all authors providing critical comments and revisions. All authors have read and approved the final version.

\section{Acknowledgements}

JAJ is a Senior Scholar with Alberta Innovates-Health Solutions and a Centennial Professor at the University of Alberta. SRM is a Health Scholar funded by Alberta Innovates-Health Solutions and holds the Endowed Chair in Patient Health Management funded by the Faculties of Medicine and Dentistry and Pharmacy and Pharmaceutical Sciences of the University of Alberta. This work was supported in part by contract from Alberta Health and Wellness, and a CIHR Team Grant to the Alliance for Canadian Health Outcomes Research in Diabetes (reference \#: OTG- 88588), sponsored by the CIHR Institute of Nutrition, Metabolism and Diabetes (INMD).

\section{Author details}

${ }^{1}$ Department of Public Health Sciences, University of Alberta, Edmonton, Canada. ${ }^{2}$ ACHORD, University of Alberta, Edmonton, Canada. ${ }^{3}$ Department of Medicine, University of Alberta, Edmonton, Canada. ${ }^{4}$ Alberta Health Services, Edmonton, Canada. ${ }^{5}$ Department of Psychiatry, University of Alberta, Edmonton, Canada. ${ }^{6}$ Department of Psychiatry and Behavioral Sciences, University of Washington, Seattle, WA, USA.

Received: 6 March 2012 Accepted: 3 August 2012

Published: 16 August 2012

\section{References}

1. Ali S, Stone MA, Peters JL, Davies MJKK: The prevalence of co-morbid depression in adults with type 2 diabetes: a systematic review and meta-analysis. Diabet Med 2006, 23(11):1165-1173.

2. Goldney R, Fisher P, Phillips LDW: Diabetes, depression, and quality of life: a population study. Diabetes Care 2004, 27(5):1066-1070.

3. Carnethon M, Kinder L, Fair J, Stafford R, Fortmann S: Symptoms of depression as a risk factor for incident diabetes: findings from the National Health and Nutritional Examination Epidemiologic Follow-Up Study, 1971-1992. Am J Epidemiol 2003, 158(5):416-423.

4. Brown LC, Majumdar SR, Newman SC, Johnson JA: History of depression increases risk of type 2 diabetes in younger adults. Diabetes Care 2005, 28(5):1063-1067.

5. Knol MJ, Twisk JW, Beekman AT, Heine RJ, Snoek FJ, Pouwer F: Depression as a risk factor for the onset of type 2 diabetes mellitus. A meta-analysis. Diabetologia 2006, 49(5):837-845.

6. Ciechanowski P, Katon WJ, Russo J: Depression and diabetes: impact of depressive symptoms on adherence, function, and costs. Arch Intern Med 2000, 160(21):3278-3285. 
7. Lustman P, Anderson R, Freedland K, DeGroot M, Carney R, Clouse R: Depression and glycemic control: A meta-analysis review of the literature. Diabetes Care 2000, 23(7):934-942

8. DeGroot M, Anderson R, Freedland K, Clouse R, Lustman PJ: Association of depression and diabetes complications: a meta-analysis. Psychosomatic Medicine 2001, 63(4):619-630

9. Black S, Markides K, Ray L: Depression predicts increased incidence of adverse health outcomes in older persons with type 2 diabetes. Diabetes Care 2003, 26(10):2822-2828.

10. Ciechanowski P, Katon W, Russo JHH: The relationship of depressive symptoms to symptom reporting, self-care and glucose control in diabetes. General Hospital Psychiatry 2003, 25(4):246-252.

11. McKellar J, Humphreys K, Piette J: Depression increases diabetes symptoms by complicating patients' self-care adherence. The Diabetes Educator 2004, 30(3):485-492.

12. Grey $M$, Whittemore $R$, Tamborlane W: Depression in type 1 diabetes in children: natural history and correlates. J Psychosom Res 2002, 53(4):907-911.

13. Ali S, Stone M, Skinner TC, Robertson N, Davies MKK: The association between depression and health-related quality of life in people with type 2 diabetes: a systematic literature review. Diabetes Metab Res Rev 2010, 26(2):75-89.

14. Egede L, Zheng D, Simpson K: Comorbid depression is associated with increased health care use and expenditures in individuals with diabetes. Diabetes Care 2002, 25(3):464-470.

15. Simon G, Katon W, Lin E, et al: Diabetes complications and depression as predictors of health care costs. General Hospital Psychiatry 2005, 27(5):344-351.

16. Lustman P, Griffith L, Clouse R: Depression in adults with diabetes: results of a 5-year follow-up study. Diabetes Care 1988, 11(8):605-612.

17. Wang J, Schmitz N, Dewa C: Socioeconomic status and the risk of major depression: the Canadian National Population Health Survey. Journal of Epidemiology and Community Health 2009, 64(5):447-452.

18. Katon W, Simon G, Russo J, et al: Quality of depression care in a population-based sample of patients with diabetes and major depression. Medical Care 2004, 42(12):1222-1229.

19. Remick RA: Diagnosis and management of depression in primary care: a clinical update and review. CMAJ 2002, 167(11):1253-1260.

20. Robinson WD, Geske JA, Prest LA, Barnacle R: Depression treatment in primary care. Journal of American Board Family Practice 2005, 18(2):79-86.

21. Katon W, Von Korff M, Ciechanowski P, Russo J, Lin E, Simon G: Behavioral and clinical factors associated with depression among individuals with diabetes. Diabetes Care 2004, 27(4):914-920.

22. Grant $R$, Hamrick H, Sullivan C, Dubey A, Chueh H, et al: Impact of population management with direct physician feedback on care of patients with type 2 diabetes. Diabetes Care 2003, 26(8):2275-2280

23. Phillips C, Wright S, Kern D, Singa R, Shepperd S, Rubin H: Comprehensive discharge planning with post discharge support for older patients with congestive heart failure: a meta-analysis. JAMA 2004, 291(11):1358-1367.

24. Renders C, Valk G, Griffin S, Wagner E, Eijk Van J, Assendelft W: Interventions to improve the management of diabetes in primary care, outpatient, and community settings: a systematic review. Diabetes Care 1995, 24(10):1821-1833.

25. Shojania KG, Ranji SR, MCDonald KM, Grimshaw JM, Sundaram V, Rushakoff RJ, Owens DK: Effects of quality improvement strategies for type 2 diabetes on glycemic control: a meta-regression analysis. JAMA 2006, 296(4):427-440.

26. Gilbody S, Bower P, Fletcher J, Richards D, Sutton A: Collaborative care for depression: a cumulative meta-analysis and review of longer-term outcomes. Arch Intern Med 2006, 166(21):2314-2321.

27. van der Feltz-Cornelis CM, Nuyen J, Stoop C, Chan J, Jacobson AM, Katon W, Snoek F, Sartorius N: Effect of interventions for major depressive disorder and significant depressive symptoms in patients with diabetes mellitus: a systematic review and meta-analysis. General Hospital Psychiatry 2010, 32(4):380-395.

28. Katon WJ, Von Korff M, Lin EH, Simon G, Ludman E, Russo J, Ciechanowski P, Walker E, Bush T: The Pathways Study: a randomized trial of collaborative care in patients with diabetes and depression. Arch Gen Psychiatry 2004, 61(10):1042-1049.

29. Katon WJ, Lin EH, Von Korff M, Ciechanowski P, Ludman EJ, Young B, Peterson D, Rutter CM, McGregor M, McCulloch D: Collaborative care for patients with depression and chronic illnesses New England Journal of Medicine 2010, 363:2611-2620.
30. Katon W, Russo J, Lin EHB: Cost effectiveness of a multicondition collaborative care intervention: A randomized controlled trial. Arch Gen Psychiatry 2012, 69(5):506-514.

31. Glasgow R, Vogt T, Boles S: Evaluating the public health impact of health promotion interventions: the RE-AIM framework. Am J Public Health 1999 89(9):1322-1327.

32. Relton C, Torgerson D, O'Cathain A, Nicholl J: Rethinking pragmatic randomised controlled trials: introducing the "cohort multiple randomised controlled trial" design. BMJ 2010, 340:c1066.

33. Tunis S, Stryer D, Clancy C: Practical clinical trials: increasing the value of clinical research for decision making in clinical and health policy. JAMA 2003, 290(12):1624-1632

34. MacPherson H: Pragmatic clinical trials. Complementary Therapies in Medicine 2004, 12(2-3):136-140.

35. Zwarenstein M, Treweek S, Gagnier J, Altman D, Tunis S, Haynes B, Oxman AD Moher D: Improving the reporting of pragmatic trials: an extension of the CONSORT statement. BMJ 2008, 337(a2390).

36. Shojania KG, Ranji SR, McDonald KM, Grimshaw JM, Sundaram V, Rushakoff RJ, Owens DK: Effects of quality improvement strategies for type 2 diabetes on glycemic control: a meta-regression analysis. JAMA 2006, 26(296):427-440.

37. Treweek S, Zwarenstein M: Making trials matter: pragmatic and explanatory trials and the problem of applicability. Trials 2009, 10(37).

38. Rittenhouse DSS: The patient-centered medical home. JAMA 2009, 301(19):2038-2040

39. Weingarten SR, Riedinger MS, Conner L, Lee TH, Hoffman I, Johnson B, Ellrodt AG: Practice guidelines and reminders to reduce duration of hospital stay for patients with chest pain - an interventional trial. Ann Intern Med 1994, 120(4):257-263.

40. Cochrane Effective Practice and Organization of Care Group (EPOC) resources for review authors. Accessed 15 February 2011. http://epoc.cochrane.org/ epoc-resources-review-authors.

41. Majumdar SR, Rowe BH, Folk D, Johnson JA, Holroyd BH, Morrish DW, Maksymowych WP, Steiner I, Harley CH, Wirzba B, et al: A controlled trial to increase detection and treatment of osteoporosis in older patients with a wrist fracture. Ann Intern Med 2004, 141(5):366-373.

42. Rucker D, Rowe BH, Johnson JA, Steiner IP, Russell AS, Hanley DA, Maksymowych WP, Holroyd BR, Harley CH, Morrish DW, et al: Educational intervention to reduce falls and fear of falling in elderly patients after fragility fracture: results of a controlled pilot study. Preventive Medicine 2006, 42(4):316-319.

43. Manea L, Gilbody S, McMillan D: Optimal cut-off score for diagnosing depression with the Patient Health Questionnaire (PHQ-9): a metaanalysis. CMAJ 2011, 184(3):E191-E196.

44. Kroenke K: Enhancing the clinical utility of depression screening. CMAJ 2012, 184(3):281-282

45. van Steenbergen-Weijenburg KM, de Vroege L, Ploeger RR, Brals JW, Vloedbeld MG, Veneman TF, Hakkaart-van Roijen L, Rutten F, Beekman AT, van der Feltz-Cornelis CM: Validation of the PHQ-9 as a screening instrument for depression in diabetes patients in specialized outpatient clinics. BMC Heal Serv Res 2010, 10:235.

46. Bell A, D'Zurilla T: Problem solving therapy for depression: A metaanalysis. Clin Psychol Rev 2009, 29(4):348-353.

47. Arean $P$, Hegel M, Vannoy S, Fan M, Unuzter J: Effectiveness of problem solving therapy for older, primary care patients with depression: Results from the IMPACT project. Gerontologist 2008, 48(3):311-323.

48. Mynors-Wallis L, Gath D, Llyoyd Thomas A, Tomlinson D: Randomized controlled trial comparing problem solving treatment with amitriptyline and placebo for major depression in primary care. British Medical Journal 1995, 310(6977):441-445.

49. Cuijpers $P$, van Straten A, Warmerdam L: Problem solving therapies for depression: A meta-analysis. European Psychiatry 2007, 22(1):9-15.

50. Jacobson N, Martell C, Dimidjian S: Behavioral activation treatment for depression: Returning to contextual roots. Clin Psychol Sci Pract 2001, 8(3):255-270.

51. Gortner E, Gollan J, Dobson K, Jacobson N: Cognitive behavioral treatment for depression: Relapse prevention. J Consult Clin Psychol 1998, 66(2):377-384

52. Jacobson N, Dobson K, Truax P. Addis M, Koerner K, Gollan J, et al: A component analysis of cognitive-behavioral treatment for depression. J Consult Clin Psychol 1996, 64(2):295-304. 
53. Jacobson N, Gortner E: Can depression be demedicalized in the 21st century? Scientific revolutions, counter revolutions and the magnetic field of normal science. Behav Res Ther 2000, 38(2):103-117.

54. Simons A, Garfield S, Murphy G: The process of change in cognitive therapy and pharmacotherapy: Changes in mood and cognition. Arch Gen Psychiatry 1984, 41(1):45-51.

55. Rollnick S, Miller W: What is motivational interviewing? Behavioral and Cognitive Psychotherapy 1995, 23(4):325-334.

56. Burke B, Arkowitz H, Menchola M: The efficacy of motivational interviewing: A meta-analysis of controlled clinical trials. J Consult Clin Psychol 2003, 71(5):843-861.

57. Rubak S, Sandbæk A, Lauritzen T, Christensen B: Motivational interviewing: a systematic review and meta-analysis. Br J Gen Pract 2005, 55(513):305-312.

58. Pouwer F, Tack CJ, Geelhoed-Duijvestin PHLM, Bazelmans E, Beekman AT, Heine RJ, Snoek FJ: Limited effect of screening for depression with written feedback in outpatients with diabetes mellitus: a raondomized controlled trial. Diabetologia 2011, 54(4):741-748.

59. Majumdar SR, Guirguis LM, Toth EL, Lewanczuk RZ, Lee TK, Johnson JA: Controlled trial of a multifaceted intervention for improving quality of care for rural patients with type 2 diabetes. Diabetes Care 2003, 26(11):3061-3066.

60. Majumdar SR, Johnson JA, Bowker SL, Booth GL, Dolovich L, Ghali W, Harris SB, Hux JE, Holbrook A, Lee $H$, et al: A Canadian consensus for the standardized evaluation of quality improvement interventions in type 2 diabetes: Development of a Quality Indicator Set. Canadian Journal of Diabetes 2005, 29(3):220-229.

61. Johnson JA, Pickard AS: Comparison of the EQ-5D and SF-12 in a general population survey in Alberta, Canada. Med Care 2000, 38(1):115-121.

62. Johnson JA, Maddigan SL: Performance of the RAND-12 and SF-12 summary scores in type 2 diabetes. Quality of Life Research 2004, 13(2):449-456.

63. Johnson JA, Luo N, Shaw JW, Kind P, Coons SJ: Valuations of EQ-5D health states: are the United States and United Kingdom different? Med Care 2005, 43(3):221-228.

64. Shaw JW, Johnson JA, Coons SJ: US valuation of the EQ-5D health states: development and testing of the D1 valuation model. Medical Care 2005, 43(3):203-220

65. McGuire BE, Morrison TG, Hermanns N, et al: Short-form measures of diabetes-related emotional distress: the Problem Areas in Diabetes Scale (PAID)-5 and PAID-1. Diabetologia 2010, 53(1):66-69.

66. Gordon A, Maisto S, McNeil M, et al: Three questions can detect hazardous drinkers. J Fam Pract 2001, 50(4):313-320.

67. Smith P, Schmidt S, Allensworth-Davies D, Saitz R: A single-question screening test for drug use in primary care. Arch Intern Med 2010, 170(13):1155-1160.

68. Godin G, Shephard R: A simple method to assess exercise behavior in the community. Canadian Journal of Applied Sport Sciences 1985, 10(3):141-146.

69. Toobert DJ, Hampton SE, Glasgow RE: The Summary of Diabetes Self-Care Activities Measure: results from 7 studies and a revised scale. Diabetes Care 2000, 23(7):943-950.

70. Overview of the Questionnaires, Document No. 350. In Edited by Survey CCG. CAHPS ${ }^{\circledR}$ Updated 8/19/2008: https://www.cahps.ahrq.gov/cahpskit/ cahpskit_main.asp.

71. Glasgow RE, Whitesides H, Nelson CC, King DK: Use of the Patient Assessment of Chronic Illness Care (PACIC) with diabetic patients: relationship to patient characteristics, receipt of care, and selfmanagement. Diabetes Care 2005, 28(11):2655-2661.

72. Gugiu PC, Coryn C, Clark R, Kuehn A: Development and evaluation of the short version of the Patient Assessment of Chronic Illness Care instrument. Chronic Illness 2009, 5(4):268-276.

73. Chew L, Griffin J, Partin M, Noorbaloochi S, Grill J, Snyder A: Validation of screening questions for limited health literacy in a large VA outpatient population. Journal of General Internal Medicine 2008, 23(5):561-566.

74. Lorig KR, Sobel D, Ritter PL, Laurent D, Hobbs M: Effect of a selfmanagement program for patients with chronic disease. Effective Clinical Practice 2001, 4(6):256-262.

75. Roy J, Lin X, Ryan LM: Scaled marginal models for multiple continuous outcomes. Biostatistics 2003, 4(3):371-383.

76. Guyatt GH, Juniper EF, Walter SD, Griffith LE, Goldstein RS: Interpreting treatment effects in randomised trials. BMJ 1998, 316(7132):690-693.

77. Johnson JA, Balko SU: Chapter 4, Diabetes and Health Care Utilization in Alberta. In Alberta Diabetes Atlas 2011. Edited by Johnson JA.: Edmonton, AB; Institute of Health Economics; 2011:35-58.
78. Katon W, Unutzer J, Fan M, Williams J, Schoenbaum M, Lin E: Cost-effectiveness and net benefit of enhanced treatment of depression for older adults with diabetes and depression. Diabetes Care 2006, 29(2):265-270.

79. Simon G, Katon J, Lin E, et al: Cost-effectiveness of systematic depression treatment among people with diabetes mellitus. Arch Gen Psychiatry 2007, 64(1):65-72.

80. Katon W, Russo J, Von Korff M, Lin E, Ludman E, Ciechanowski P: Long-term effects on medical costs of improving depression outcomes in patients with depression and diabetes. Diabetes Care 2008, 31(6):1155-1159.

81. Lau R, Ohinmaa A, Johnson JA: Predicting the Future Burden of Diabetes in Alberta from 2008 to 2035. Canadian Journal of Diabetes 2011, 35(3):274-281.

82. Majumdar SR, Lier SA, Rowe BH, Russell AS, McAlister FA, Maksymowych WP Hanley DA, Morrish DW, Johnson JA: Cost-effectiveness of a multi-faceted intervention to improve quality of osteoporosis care after wrist fracture. Osteoporos International 2011, 22(6):1799-1808.

83. Simpson SH, Johnson JA, Tsuyuki RT: Economic impact of community pharmacist intervention in cholesterol risk management: An evaluation of the study of cardiovascular risk intervention by pharmacists (SCRIP). Pharmacotherapy 2001, 21(5):627-635.

84. Thomas DR: A general inductive approach for analyzing qualitative evaluation data. Am J Eval 2006, 27(2):237-246.

85. Starks H, Trinidad SB: Choose your method: a comparison of phenomenology, discourse analysis and grounded theory. Qual Heal Res 2007, 17(10):1372-1380.

86. Mayan MJ: Essentials of Qualitative Inquiry. Walnut Creek, CA: Left Coast Press In. 2009.

87. Tri-Council Policy Statement: Ethical Conduct for Research Involving Humans http://www.pre.ethics.gc.ca/eng/policy-politique/initiatives/tcps2-eptc2/ Default/.

doi:10.1186/1472-6963-12-258

Cite this article as: Johnson et al.: Controlled trial of a collaborative primary care team model for patients with diabetes and depression: Rationale and design for a comprehensive evaluation. BMC Health Services Research 2012 12:258.

\section{Submit your next manuscript to BioMed Central and take full advantage of:}

- Convenient online submission

- Thorough peer review

- No space constraints or color figure charges

- Immediate publication on acceptance

- Inclusion in PubMed, CAS, Scopus and Google Scholar

- Research which is freely available for redistribution 